\title{
Study on safety monitoring information platform based on Internet of things
}

\author{
Wuli Song ${ }^{1, \mathrm{a} *}$ \\ ${ }^{1}$ College of Information Engineering,Taishan Medical \\ University,Taian,Shandong 271016,China \\ ${ }^{a}$ Authors to whom correspongence should be \\ addressed.Electronic addresses:songswl@163.com \\ * the corresponding author \\ Jing Qiao ${ }^{1}$ \\ ${ }^{1}$ College of Information Engineering,Taishan Medical \\ University,Taian,Shandong 271016,China
}

\begin{abstract}
Objective: This article based on the analysis of system and system thinking as the foundation, through to the existing problems of coal mine safety monitoring system for a comprehensive analysis of the system, points out the existing problems of China's coal mine safety monitoring system, and expounds the various subsystems need to build coal mine safety networking system, and then combined with the Internet of things technology design perfect and meet the needs of coal mine safety monitoring system for coal demand of Internet of things. Methods: Based on the course of development of security technology in China coal mine the elaboration, pointed out the main problems which exist; results: analyzed the application status of Internet of things technology in safety monitoring system in our country in the coal mine, and points out the main problems existing in the application process. Conclusion: and then on this basis, combined with the basic framework of coal mine safety of Internet of things, build up the application model of coal mine safety of Internet of things.
\end{abstract}

Keywords- coal mine; safety monitoring; Internet of things; system design

Fund Project: National Safety Supervision Bureau of production safety accident prevention in 2015 major key science and technology project（shandong-0138-2015AQ）

According to the "2012 China Coal Industry Yearbook" statistics, the existing coal mine in our country is about 25000, but the individual Township Coal Mines coal mine, there are 23000 . The lack of safety equipment and management measures of large coal mine these small coal mines, the production safety situation is not optimistic. The total amount of coal mine accidents in China at the present stage is still high, all kinds of illegal production of coal mine accidents, major accidents still occur in the constant, especially in small coal mine accident rate accounted for the national coal mine safety accidents occurred above, the rate of $70 \%$ above, coal mine safety situation in China is very serious. Coal mine

\author{
Linna $\mathrm{Li}^{2}$ \\ ${ }^{2}$ Shandong Agricultural University,Taian,Shandong \\ 271016,China \\ Lei Peng ${ }^{1}$ \\ ${ }^{1}$ College of Information Engineering,Taishan Medical \\ University,Taian,Shandong 271016,China \\ Min Feng ${ }^{1}$ \\ ${ }^{1}$ College of Information Engineering,Taishan Medical \\ University, Taian,Shandong 271016,China
}

safety monitoring system can better supervision and management of coal mine enterprise, make the safety accidents to a minimum[1].

\section{IN COAL MINE SAFETY MONITORING SYSTEM IN OUR COUNTRY THE PROBLEM}

\section{A. A single product monitoring object}

Early device can only simple monitoring of gas, the need for manual operation, heavy and low sensitivity; in 80 years, China has introduced a series of coal mine safety monitoring products from abroad, so that China's coal mine safety monitoring level is improved, but these products are only for a certain physical parameters gas, temperature, mechanical coal mine monitoring, monitoring of these early products lack of personnel positioning, personnel work, to the work process, so gradually be eliminated. 90 in the development of WEBGIS and other products, and it is also one of the function module of coal mine safety networking system integration at present, realizes the visualization management of the coal mine, but the monitoring object focused on specific object form, such as the environment, personnel, lack of monitoring for all kinds of abstract object. A single product monitoring object, which limits the comprehensive automation level of the enterprise to improve the monitoring object, rich and comprehensive, is currently the problems focus on domestic coal mine monitoring technology.

\section{B. The high cost of construction and maintenance}

At present, many of the application of product safety monitoring system of coal mine in our country, and the system structure of various types of construction has many kinds of products, mainly distributed control system, while improving the automation level of coal mine safety monitoring, but in the process of its construction and maintenance problems is very much, has brought a lot of 
difficulties for users to use and maintenance. But there is a disadvantage of decentralized control system is difficult to realize the interconnection of each module and interoperability, sharing to realize information.

\section{The lack of intelligent diagnosis function of remote maintenance and fault}

In recent years, coal enterprises with advanced technology application degree deepening, the informatization construction in coal enterprises in China have also made certain achievements. However, with the increase of the content of science and technology equipment, complex technology is also increased, also increased the difficulty of maintenance and fault diagnosis. The various kinds of intelligent fault diagnosis function of remote maintenance and fault can be timely diagnosis of safety production of coal mine, and remote maintenance, which to a great support to improve the coal mine enterprise production efficiency, the key point is the coal enterprises and related manufacturers demand research and development.

\section{Do not have decision support system}

All kinds of safety information system in our country at present development, its only as an isolated system is applied, the lack of comprehensive function of accident control and safety information system, all kinds of safety information system of coal mining enterprises in China are being used as isolated database and contact each software package, the lack of overall planning. This leads to these products cannot meet the safety management in the coal enterprise to the decision-making of the whole control requirements, unable to support the coal mine managers manage the whole of the coal mine, it is difficult to improve the overall level of safety management in coal mine.

\section{APPLICATION OF THE INTERNET OF THINGS TECHNOLOGY IN SAFETY MONITORING SYSTEM OF COAL MINE}

Because of the Internet of things is the beginning of the twenty-first Century the rise of the industry, the relative lack of historical data. The technical level of coal mine safety of Internet of things directly reflects the level of comprehensive automation level of coal mine.

\section{A. The heavy technical, light management and training}

The Internet of things technology as currently the most advanced technology, many coal enterprises in through the relevant technology manufacturers Building networking monitoring system, thought to have advanced technology as support, we can neglect management, often lack the networking technology related knowledge and skills training of talents, and the lack of networking monitoring system and matching management, thus network monitoring system has led to the lack of management, related technology and equipment material is difficult to play its due function.

\section{B. The lack of public open platform}

At present, most of the Internet of things technology Related Companies and software development company, its out of their own business purposes, monopoly in order to achieve its own, often in communication network and its products all adopt the special standard, leading to its products with the upper Internet information network, and between the system of other products to achieve network interconnection, sharing more it is difficult to realize the information.

\section{The lack of application level information fusion}

Due to coal mine Internet of things system in the development process, the lack of development and application of every aspect of information fusion system, which leads to the lack of application layer information fusion. Information fusion as the information processing mode of a multifaceted, multi-level, the detection, the combination of multi-source data, so as to complete the application, as a high level application system, which plays a decisive role in the level of integrated automation system[2].

\section{Pan in the perceived lack of network}

Pan is a basic feature of the Internet of things in, mainly refers to the wireless network coverage of the ubiquitous, as well as the wireless sensor network, the RFID logo and other means of ubiquitous sensing. The Internet of things pan that two problems: first, in the comprehensive data acquisition is the basic function of the realization of the Internet of things; second, the key is to solve the IOT promotion of low power consumption, low cost and miniaturization problem [3]. Before China's various types of coal mine Internet of things basically no unified underground wireless coverage layer perceptron network, current sensor and monitoring methods can not be applied to the coal flow operation, dangerous source location, distribution, and its flow pattern are uncertain situations, and the existence of the perception of large blind zone.

\section{E. Monitoring subsystem is not complete}

Through the inspection after a large number of China's coal mine safety networking monitoring system construction case found that the monitoring system are not complete, the coal mine enterprise monitoring system will lead to lack of corresponding function not complete, thus affecting the normal operation of the relevant functions of coal mine. For all kinds of problems in China's coal mine safety monitoring system, and through the analysis of coal mine enterprise of Internet of things system now, know that the lack of monitoring subsystem monitoring subsystem mainly coal mine safety networking system and related enterprises, will be based on the existing problems and gives the requirements of design, integration of the main monitoring subsystem, detailed design process coal mine safety monitoring system are the Internet of things technology application of the Internet of things of a relatively complete. 


\section{DESIGN OF NETWORK MONITORING SYSTEM OF COAL MINE SAFETY MATTER}

The above has been on the concept of Internet of things and IOT application status in the safety monitoring system of coal mine in our country is analyzed in detailed description of the system, there have been more clear understanding of it, the following will be combined with the Internet of things technology, analysis of the main problems existing in the process of China's coal mine safety in the system construction and the previous design of coal mine safety, a relatively complete system of Internet of things.

\section{A. The model design of network monitoring system of coal mine safety matter}

Based on the coal mine safety monitoring system of the Internet of things is mainly composed of 3 aspects, including the perception layer, specifically the information acquisition and application layer; transport layer, is the transport layer data information; the following the network architecture based on, combined with China's coal mine safety problems in the application of the Internet of things, based on the above on the analysis of the demand, design of for coal mine safety networking model[4].

Through the above analysis, the overall structure of network monitoring system of coal mine safety materials can be divided into three levels, respectively is the perception and control layer, information integration layer and management decision-making application layer, combined with the enterprise demand analysis, here will be based on three layers of basic structure, adding information presentation layer, as the portal system of enterprise[5] .

According to the coal mine safety monitoring system contains subsystems and need to build, the following will all the levels of the need to build elaborate content.

1) perceptual control layer

In order to achieve simultaneously scalar information and all kinds of video, audio and other vector information, change with age produced a wireless multimedia network in coal mines. The wireless multimedia network will process the information collection and use more image, recognition, fusion technology to handle all kinds of information, so as to meet the diversified needs of application in coal mining[6] .

\section{2) data transmission integration layer}

In the basic characteristics of network database structure construction based on matter, combined with the actual situation of literature research and the safety in production of coal mine, on the two data module data to improve and complement the obtained database system are as follows, including various database system data: industrial level database: data module includes the expert data and fault diagnosis data, linkage control strategy, data analysis etc.. Relational database: data module including the management of basic data, data organization, business standard data, expert knowledge such as data[7].

3) management application layer
Coal enterprise management application layer is divided into two basic categories, one category is according to the safety management module of mine production, one is for business management module of enterprise management.

Intelligent security management basing on the traditional module after supplementation of divided into six categories, respectively is: information security management of the Internet of things; management of coal mine safety evaluation; electromechanical equipment management: including the mine ventilation system, mining system, power supply system, fire proof and dust-proof facilities etc. The management module is mainly for the management of examination, all kinds of mechanical and electrical equipment in coal mine maintenance, maintenance work; major hazards management. This module is the basic guarantee for the safety of coal production, the effective operation of the module to the positive role in promoting the level of coal mine safety work enhancement; mine environment information management. This module as the basic construction of every module in mine, is the fundamental guarantee of the mine safety production; navigation analysis management: location and navigation coal mine supporting system, the main work is to mine staff, transportation system positioning, information collection.

The business intelligence management system contains the work here is divided into six categories, respectively is: the project management: safety engineering major construction work, including project management information system construction, transport system construction. Project management is mainly responsible for various projects of coal enterprise shelves, facilities and security work; production scheduling management: the main work of the production scheduling management of personnel management, work time management, task management, its main task is to guarantee the coal mine daily production smoothly; financial assets; Human Resource Management; logistics management; expert decision support: expert decision support system is the establishment of various kinds of expert decision support database, so as to help the coal enterprise decision makers to improve decision level and quality[8].

4) information presentation layer

Information presentation layer as the portal system of the enterprise, its main function is the realization of the internal and external enterprise information display, not in detail here.

\section{B. Design of network monitoring system network structure of coal mine safety matter}

Through the above design coal mine safety monitoring system model of the Internet of things, has been clear about the network monitoring system of coal mine safety by the structure of four layers network composed of coal mine production, combined with all kinds of devices in the transitive network, there will be for coal mine safety network architecture network monitoring system design 
[9]. This network architecture as the foundation, combined with the model of coal mine safety of Internet of things, its complement, and then set up a relatively complete network architecture diagrams.

Coal mine safety of Internet of things system network architecture can be divided into two parts of underground and surface coal mine in part, main network access is the underground underground facilities and equipment, including conveyor, scavenging pump, water pump, underground pressure fan, substation, monitoring video, communication base station, and sensor, the various types of equipment facilities of the signal through the industrial Ethernet Switch Ethernet ring network access to the underground, and then output to the ground, and then realize the transmission of downhole data information and receiving. Equipment ground mainly include ground sensor, video monitoring, industrial TV, substation, surface wind machine, engineer station, redundant servers, all kinds of facilities and equipment to the ground is the same access through industrial Ethernet receiving and controlling of underground data, but also through the switch to realize the management system of coal mine data transmitting and receiving [10]. System installation of fiber optic cable according to the demand and redundancy Industrial Ethernet ring net is made of fire-retardant cable. Industrial Ethernet ring net in addition to access a variety of monitoring and control system, but also the wireless mobile phone, telephone, wired IP personnel positioning system and digital video system access network. In the system of ground and underground subsystems via backbone network through the interconnection of industrial Ethernet interface of industrial grade switch[11] .

Network monitoring system of the coal mine safety substance network architecture design, based on an integrated mine "three sense" core, respectively is the perception, perception, the perception of environmental equipment personnel three, into production monitor and management decision system, and based on the cloud service platform, the security intelligence analysis (including network information security management, coal mine safety evaluation management, management of electrical and mechanical equipment, major disaster prevention management) analysis and business intelligence (financial management, project management, production scheduling management, expert personnel system management) together, thus greatly improve the integrated automation level of mining the overall [12].

The Internet of things in this coal mine safety intelligent monitoring system architecture design process, combined with the problems existing in our country's coal mine safety construction of Internet of things noted, and the specific needs of enterprises, put forward specific requirements are: coal system of various information can thaw the bone dry network transmission, cannot exist isolated island of information; the establishment of special network virtual according to various subsystems each monitoring system, so as to guarantee the various subsystems can be relatively independent operation; multi control system for the establishment of a unified network, transmission of each department and the local center of data through the network, so as to achieve the effective control of the data of each part of the system; system with hot plug structure, modular then let mine, can effectively repair, maintenance and upgrade work; unified programming configuration system, improve the compatibility of the system[13].

\section{CONCLUSION}

In this paper, through the analysis of on at home and abroad research status of network transitive network based on application status of safety monitoring system of coal mine in our country, points out the existing traditional our country coal mine monitoring system in question, the present defects and coal mine safety monitoring system of the Internet of things. Then based on the Internet of things technology, designed the coal mine safety monitoring system of the relative improvement of the Internet of things[14].

Through research and analysis, this paper obtains the following conclusions:

One is the present situation of various monitoring system at present of our country coal mine safety monitoring applications in the field of this paper made a systematic analysis, points out their structure and function and other aspects of the shortcomings and problems.

The two is the article on the existing coal mine safety monitoring system on the basis of analyzing problems, combined with the basic characteristics of IOT, designed the model of coal mine safety monitoring system based on Internet of things.

\section{REFERENCE}

[1] Chang F, Dean J, Ghemawat S, et al. Bigtable: A distributed storage system for structured data[J]. ACM Transactions on Computer Systems (TOCS), 2008, 26(2): 4.

[2] Xiqing Liu.On the current situation and development of domestic coal mine gas monitoring system $[\mathrm{J}]$. Shanxi coking coal science and technology, 2006 (3):37-40. [3] Zhaojin Cai.Discussion on China's coal mine safety monitoring system[J]. Modern coal mines, 2006 (3): 27-28.

[4] Dong Liu. Design of intelligent mine system based on Internet of things[J]. The technology of the Internet of things, 2013, 3(9): 61-64.

[5] Li Jia, Weijian Sun. Application of structural analysis of mine Internet of things[J]. Inner Mongolia coal economy, 2012 (8): 54-55.

[6] Qizhong Zhang, Peng Huang, Jianguo Yu.In the mine production safety application design of monitoring of Internet of things[J]. Value engineering, 2013, 32(12): 206-208.

[7] Wei Zhang, Xiaofei Yan, Zheng Yang.To explore the ancient city construction based on the wisdom of the Internet of things[J]. Journal of Zaozhuang University, 2013, 30(2): 8-13.

[8] Dong Liu. Design and research of network model of coal based on system dynamics[J].The technology of the Internet of things, 2013, 3(7): 69-72.

[9] Lei Zhang, Yunliang Xu, Gang Li.The perception of mine Internet of things in the construction and application of Jiahe Coal Mine[J].Chinese mining, 2012, 1.

[10] Yi Han, Peng Sang. The Internet of things technology applied in coal mining enterprises[J]. Coal mine machinery, 2013, 34(006): 241-242. 
[11] Wen Shi. Research of coal mine monitoring and control network system[D].Xi'an Electronic and Science University, 2011.

[12] Jianjun liu. Application of integrated automation technology in CuiJiaGou coal mine[J].Shaanxi coal, 2011, 30(5): 82-84.

[13] Shen Zhang, Enjie Ding.Lectures on the Internet of things and the perception of mines two sensor mine and digital mine, mine integrated automation[J]. Industrial automation , 2010 , 11:129-132.

[14] Jinling Song, Lina Hao, Pei Wei. Jiahe Coal Mine Internet of things perceived scheme design and Implementation[J]. Coal science and technology, 2012, 40(009): 68-71. 